\begin{tabular}{c} 
International Journal of Engineering \& Technology, $7(4.37)(2018)$ 150-152 \\
International Journal of Engineering \& Technology \\
WPC \\
Website www.sciencepubco.com/Index.Php/IJET \\
Research Paper \\
\hline
\end{tabular}

\title{
A Comparison Study of Performance Efficiency of Lead-Acid Batteries Available in the Iraqi Markets.
}

\author{
Hussein H. Hamed ${ }^{1}$, Iman H. Zainulabdeen ${ }^{2 *}$, Samko Sh. Raheem ${ }^{3}$, Awad E. Mohammed ${ }^{4}$ \\ ${ }^{1,4}$ Technical Institue-Hawija, Northern Technical University, Mosel, Iraq \\ ${ }^{2}$ Technical College-Kirkuk, Northern Technical University, Mosel, Iraq \\ ${ }^{3}$ Technical Institue-Kirkuk, Northern Technical University, Mosel, Iraq \\ *Corresponding author E-mail: imanhuseyin@yahoo.com
}

\begin{abstract}
Batteries consider the major important devices for energy storage based on converting the chemical energy to electrical energy. Different types of batteries are available working in different efficiencies. In this work the performance efficiency of five types of batteries available in the Iraqi were assessed. Different operating variables such as Battery Type (Akko, Raggie, Aswar, Terminator, and Hongdeng), Temperature $\left(20,25,35,45,55\right.$, and $\left.65^{\circ} \mathrm{C}\right)$, and Charging Time $(24,48$, and $72 \mathrm{hr})$ were studied the impact of these on the performance efficiency of each battery type. According to the results obtained in this study, maximum performance efficiency achieved was $7.2 \mathrm{~V}$ at optimum operating variables are (temperature $20^{\circ} \mathrm{C}$ ), and (charging time $48 \mathrm{hr}$ ). Furthermore, a computer was used with Data Logger to be connected with batteries. Finally, the most stable type and resistance to operating conditions was Aswar type in the first rank and Hongdeng type in the last rank.
\end{abstract}

Keywords: Lead-acid battery, Battery Performance, Charge Time, Temperature effect.

\section{Introduction}

One of the most important devices for energy storages are batteries. Batteries consist of electrochemical cells which convert the chemical energy to electrical energy. There are three common types of batteries available are flooded, absorbed glass mat (AGM) and gel. AGM and gel batteries are generally termed sealed or valve regulated lead acid (VRLA) (Kadiran, 2012). This type of batteries (i.e. VRLA) is one of the most important energy storage devices and the oldest were used in all over the world since 1970s and available in a variety of sizes from 1 to over 1000 ampere-hour. According to statistics, about 40 to $45 \%$ of the VRLA represents the sales value of all batteries in the world (Vutetakis, 2001). Approximately, $60 \%$ of the weight of an automotive-type lead-acid battery rated around 60 ampere-hour $(8.7 \mathrm{~kg}$ of $14.5 \mathrm{~kg}$ battery) (Linden \& Reddy, 2002). Lead acid batteries are electro-chemical storage cells and rechargeable batteries use a reversible chemical reaction to store energy. A combination of plates or grids made of lead and an electrolyte consisting of a diluted sulfuric acid to convert electrical energy into potential chemical energy and back again. Despite of having a very low energyto-weight ratio and a low energy-to-volume ratio, their ability to supply high surge currents means that the cells maintain a relatively large power-to weight ratio. It is cheapest rechargeable batteries and can produce much power a sealed lead acid battery or gel cell is a lead acid battery that has the sulfuric acid electrolyte coagulated (thickened) so it cannot spill out (Kadiran, 2012). These types of batteries can be used in various applications in many of industrial sectors such as automotive industry, renewable energy systems, portable vehicles, and also can be used extensively for energy storage, emergency power as well as for engine starting, vehicle lighting and engine ignition (Kadiran, 2012; Samolyk and
Sobczak, 2013; Gençten et al, 2016). Furthermore, these batteries can offer a valve regulation feature, allowing a safer escape of hydrogen and oxygen gasses during charging (Bukhari et al, 2015) A lead acid battery is a secondary cell meaning that comprising of lead electrode $(\mathrm{Pb})$ as an anode and lead dioxide electrode (pbo2) as a cathode immersed in sulfuric acid (H2SO4). The lead acid battery comprises of two chemically dissimilar lead based plates in a dilute sulfuric acid solution. The positive plate contains lead dioxide $\mathrm{PbO} 2$, and the negative plate pure lead in a spongy form. When immersed in dilute sulfuric acid, the nominal electric potential between the two plates is 2 volt. This voltage is universal for all lead acid batteries (Bukhari et al, 2015). The construction of VRLA does not require regular addition of water to cells and it vents less gas than flooded lead acid battery. Regarding the electrolyte part, two main electrolyte technologies have been developed by researchers such as gel electrolyte and adsorbed glass mat (AGM) systems. Sulfuric acid is adsorbed into a kind of glass mat in AGM electrolyte system and this system is called as AGMVRLA battery. The gelled electrolyte system is obtained by the mixing of gel agent (fumed silica) and optimum concentration of sulfuric acid, called as GEL-VRLA battery (Gençten et al, 2016). The performance of gel electrolyte system is better than the AGM electrolyte system especially at low and high temperature application. However, there are some misconceptions at consumer level which lead to selection of inappropriate battery type in an application which is one basic reason for poor reliability in batteries applications (Czerwińskie et al, 2014; Bukhari et al, 2015). Since their discovery by (Plante Raymond Gaston) in 1860 their energy density, change and discharge characteristics have been improved greatly (Kadiran, 2012). During the mid-1970s researchers, developed a maintenance-free lead-acid battery that could operate in any position. The liquid electrolyte was transformed into moistened separators and the enclosure was sealed. Safety valves were 
added to allow venting of gas during charge and discharge (Hutchinson, 2004). Heat is one of the most relevant problems for batteries. Actually, high temperatures have a deep impact on their performances, safety and cycle lifetime. The temperature is a main factor for battery performance. Operating temperature can affects AGM and flooded type lead acid batteries more than gel type lead acid batteries. Corrosion rate of positive grids in the GEL-VRLA is also lower than both AGM-VRLA and flooded batteries. Besides, stratification of electrolyte lowers in gelled electrolyte systems under deep-discharge cyclic application than AGM systems (Gençten et al, 2016).Therefore, it is interesting issue to be studied and analyzed for the property factor of discharge the battery (Plangklang \& Pornharuthai, 2013). It is a general perception that battery life decreases with extreme climate conditions. If we set maintenance factor identical for two different climates for a low and good quality battery, we can study overall battery quality as well. Gelled, AGM and VRLA batteries are temperature sensitive as compared to traditional flooded types which have lower heat generation and higher heat transfer rate (Bukhari et al, 2015). The life of a battery is usually expressed in number of cycles which it can deliver before its end of life. These life cycles vary from quality manufacturing process to the operating conditions of a battery. Lead-acid batteries generally are rated at $25^{\circ} \mathrm{C}$ and operate best around this temperature. Exposure to low ambient temperatures results in performance decline, whereas exposure to high ambient temperatures results in shortened life (Samolyk \& Sobczak, 2013).

Battery malfunction not only adds to the high recurring cost but also causes system failure resulting in loss of both generated power and money (Gauri et al, 2018). There are some problems occur while charging and discharging a battery. The problem is the charging process tends to undergo overcharging because typical lead acid not give signal when it fully charged. There are many types of charging and discharging method use nowadays, each one of them has its own advantages and disadvantages (Kadiran, 2012). To encounter this problem, a new method of charging and discharging technique is used. This method uses software that will cut-off the battery charging and discharging process when the maximum and minimum voltage parameter has been set. The objective of this work was to compare the performance efficiency of lead-acid batteries (Akko, Raggie, Aswar, Terminator, And Hongdeng) available in in the local Iraqi markets to select the best type of these batteries by using the process of loading and unloading with varying the temperature of the medium used by the batteries using bath water and the response received from the battery using a data logger.

\section{Materials and Methods}

In this work, all the types of batteries tested (Akko, Raggie, Aswar, Terminator, And Hongdeng) were available in the Iraqi markets with properties for each type was tabulated in Tab.1. The operating variables used in this work are temperature $(20,25,35$, 45,55 and $\left.65{ }^{\circ} \mathrm{C}\right)$, duration of batteries charging $(24,48,72 \mathrm{hr}$ ), and the type of battery. The concept of comparison performance efficiency and battery life depended mainly by using Data Logger apparatus. Detailed specifications for data logger apparatus used are shown in Tab.2.

Table 1: Tested Batteries Properties

\begin{tabular}{|l|l|l|l|}
\hline No. & $\begin{array}{l}\text { Batteries } \\
\text { name }\end{array}$ & Types & Properties \\
\hline 1 & Hongdeng & $\begin{array}{l}\text { Sealed rechargeable acid } \\
\text { battery }\end{array}$ & $6 \mathrm{~V} 4.0 \mathrm{AH}$ \\
\hline 2 & Akko & Sealed rechargeable & $\begin{array}{l}6 \mathrm{~V} \text { 4.0AH } \\
20 \mathrm{HR}\end{array}$ \\
\hline 3 & Aswar & Valve regulated battery & $6 \mathrm{~V} 4.0 \mathrm{AH}$ \\
\hline 4 & Terminator & $\begin{array}{l}\text { Sealed lead } \\
\text { Acid battery }\end{array}$ & $6 \mathrm{~V} \mathrm{4.0 \textrm {AH }}$ \\
\hline 5 & Raggie & Rechargeable sealed lead acid & $6 \mathrm{~V} \quad 4.0 \mathrm{AH}$ \\
\hline
\end{tabular}

\begin{tabular}{|l|l|}
\hline \multicolumn{1}{|c|}{ Table 2: Volt meter (Data Logger) properties } \\
\hline \multicolumn{3}{|c|}{} & battery \\
\hline No. & Data Logger \\
\hline 1 & Single-Ended, 4 Differential 12-Bit Analog Inputs. \\
\hline 2 & \pm 10 Volt Analog Input Range. \\
\hline 3 & PGA with Gains of 1, 2, 4, 5, 8, 10, 16, or 20 V/V. \\
\hline 4 & Up to 8 k Samples/Sec (Burst) or 1.2 k Samples/Second (Stream). \\
\hline 5 & Supports Software or Hardware Timed Acquisition. \\
\hline 6 & 2 Analog Outputs. \\
\hline 7 & 20 Digital I/O (Up to 50 Hz per I/O). \\
\hline 8 & 32-Bit Counter. \\
\hline 9 & USB 2.0/1.1 Low Speed HID Interface (Data Rate Information). \\
\hline 10 & Connect Up to 80 Lab Jacks to One USB Host. \\
\hline
\end{tabular}

A brief description about the experimental work performed with theses apparatus mentioned above. Initially, Connect the positive polar of resistance and positive polar of data logger with positive polar of battery and repeat the same procedure with the negative polar then connecting the data logger with the computer. Then, set the software (Daq Factory Express) by entering data and setting up channels with entering five columns and name it for each type and their number, then, click apply. Batteries are charged at different times and the data in the laboratory continues to be recorded to measure the battery voltage. The power and charge efficiency was analyzed by voltage per battery at different temperatures. The current and voltage are recorded by the computer as shown in Fig.1. The process can be repeated at different temperatures to optimize the best value of temperature.

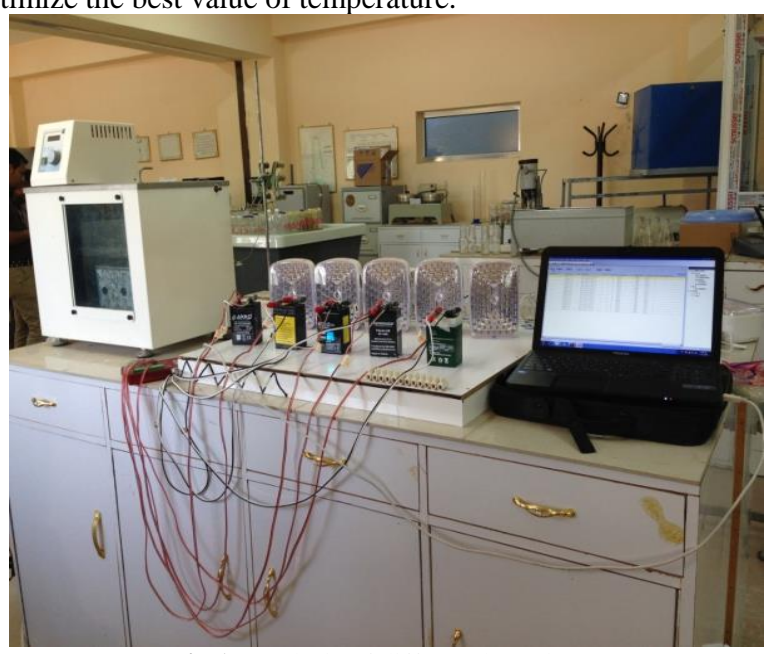

Fig.1: Analysis of different batteries process

\section{Results and Discussions}

Effect of Battery Type:The effect of battery type such as (Akko, Raggie, Aswar, Terminator, And Hongdeng) on the performance efficiency was studied in this work, as shown in Fig.2. 


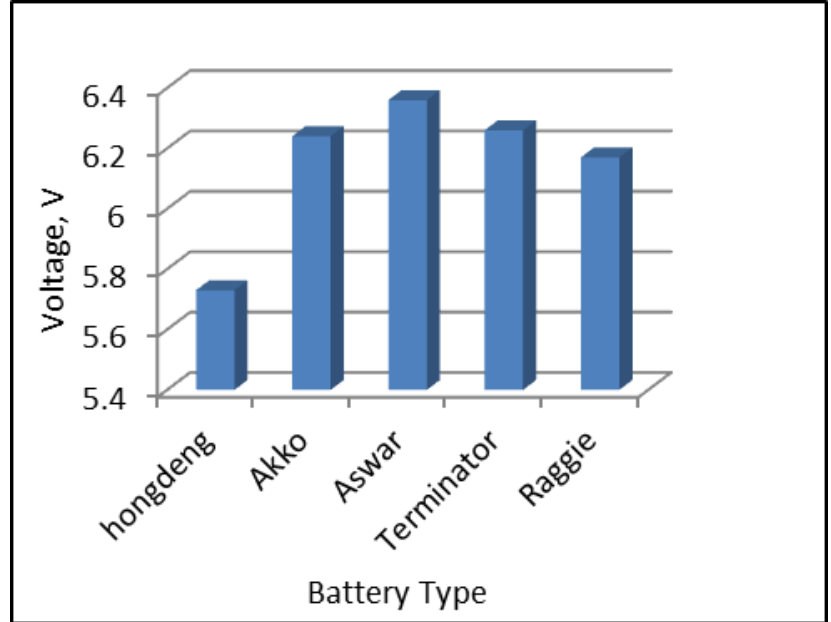

Fig.2: Effect of battery type on performance efficiency of battery at: (a) Temperature, $20^{\circ} \mathrm{C}$ (b) Charging time, 48 hour.

Based on the results obtained in Fig.2 it can be seen that, the effect of the battery type (Hongdeng, Akko, Aswar, Terminator, and Raggie ) on the performance efficiency for each type, which have been recorded in the voltage values are $5.73,6.24,6.36,6.26$ and $6.17 \mathrm{~V}$, respectively. The voltages values obtained recorded when the operating battery was $6 \mathrm{~V}$. This can be indicated that the type of Aswar has given higher voltage compared to the other types. Where, the Hong Kong type has recorded the lowest voltage value. This can be explained due to the manufacturing techniques of this type of battery. According to the results obtained in Fig.2, there was big impact of the battery type on the performance efficiency of the battery.

Effect of Temperature: The temperature can be affected significantly on the performance efficiency of the batteries tested, at different temperatures $\left(20,25,35,45,55\right.$, and $\left.65^{\circ} \mathrm{C}\right)$ (as shown in Fig.3. As can be seen from Fig.3 an increasing in temperature from 20 to $65{ }^{\circ} \mathrm{C}$ the performance efficiency for Aswar type decreased from 7.2 to $6.5 \mathrm{~V}$ respectively. The same behavior can be seen for other types. Also, Aswar battery is resistant to temperature changes clearly compared to the other types of the batteries and more stable than the other types of the species and it does not affect. These results are agree with researchers such as (Samolyk \& Sobczak, 2013). According to the results obtained, it can be say that $20^{\circ} \mathrm{C}$, the optimum temperature that achieved maximum performance efficiency.

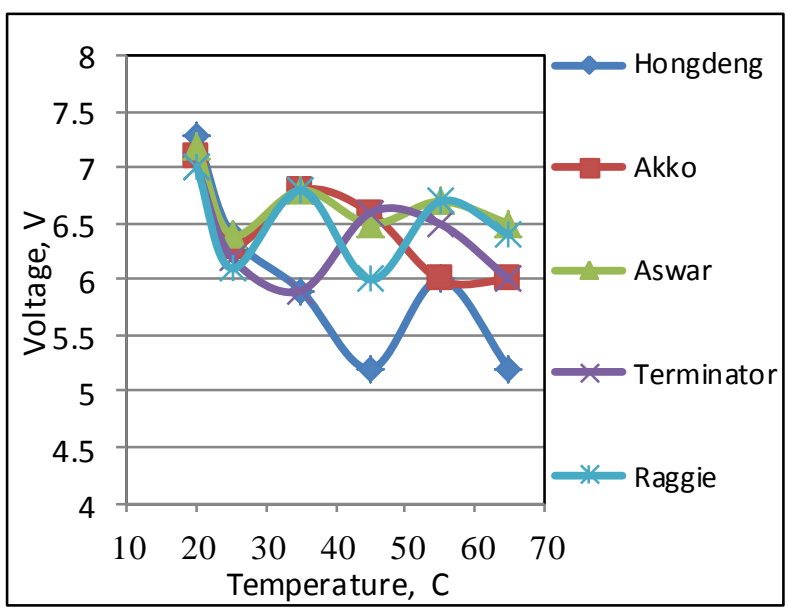

Fig.3: Effect of Temperature on performance efficiency of battery at: (a) Charging time, 48 hour (b) Various types of batteries.

3.3.Effect of Charging Time: Another important parameter affects strongly on the performance efficiency of batteries are charging time was evaluated in the period range $(24,48$, and 72 hour) as shown in Fig.4. Based on the results obtained in Fig.4 it can be seen that an increasing in the period charge of battery could lead to enhance the performance efficiency of the battery. It is noticed that maximum performance efficiency was achieved at optimum charging time was 48 hour investigated 7.2 V for Aswar battery.

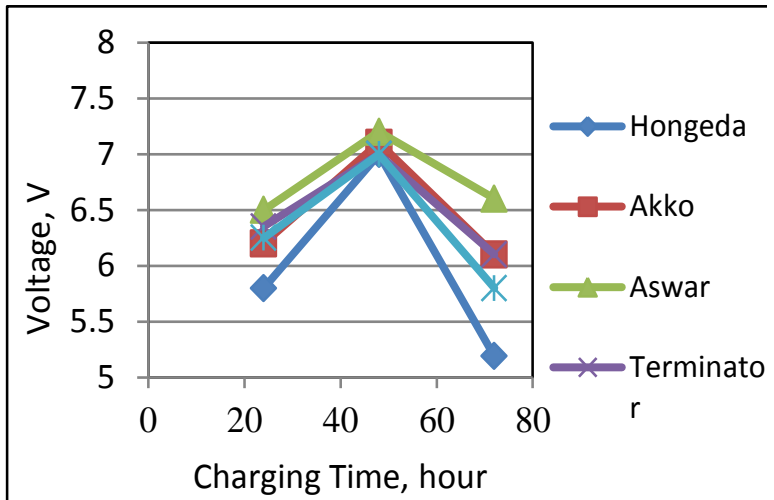

Fig.4: Effect of charging time on performance efficiency of battery at: (a) Temperature, $20^{\circ} \mathrm{C}$ (b) Various types of batteries.

\section{Conclusions}

From this study it can be concluded that the operating variables (Battery Type, Temperature, and Charging Time) have an important impact on the performance efficiency of the battery. According to the results obtained in this work, many of important conclusions are:

Some of batteries in this study have given good performance efficiency.

Low temperatures $\left(20\right.$, and $\left.25 \mathrm{C}^{\circ}\right)$ achieved better performance efficiency of battery, while higher temperatures can be reducing the performance efficiency.

Optimum charging time was 48 hour.

The best type of batteries was Aswar battery type achieved high performance efficiency compared to the other types of batteries while, Hongeda battery was the lower performance efficiency.

\section{References}

[1] Bukhari, S. M. A. S., Maqsood, J., Baig, M. Q., Ashraf, S., \& Khan, T. A. (2015, March). Comparison of Characteristics--Lead Acid, Nickel Based, Lead Crystal and Lithium Based Batteries. In Modelling and Simulation (UKSim), 17th UKSim-AMSS International Conference on (pp. 444-450). IEEE.

[2] Czerwiński, A., Rogulski, Z., Obrębowski, S., Lach, J., Wróbel, K., \& Wróbel, J. (2014). Positive plate for carbon lead-acid battery. International Journal of Electrochemical Science, 9, 48264839.

[3] Gauri, M.; Singh, B.; Pant, C., and Gairola, R. (2018). Effect Of Temperature On Flooded Lead-Acid Battery Performance. International Journal Of Advanced Science And Research, 3, 27-29.

[4] Gençten, M., Dönmez, K., \& Şahin, Y. (2016). Investigation of the temperature effect on electrochemical behaviors of $\mathrm{TiO} 2$ for gel type valve regulated lead-acid batteries. Anadolu Üniversitesi Bilim Ve Teknoloji Dergisi A-Uygulamalı Bilimler ve Mühendislik, 17(5), 882-894.

[5] Hutchinson, R. (2004). Temperature effects on sealed lead acid batteries and charging techniques to prolong cycle life (No. SAND2004-3149). Sandia National Laboratories.

[6] Kadiran, M. S. (2012). Charging and discharging methods of lead acid battery (Doctoral dissertation, UMP).

[7] Plangklang, B., \& Pornharuthai, P. (2013). Mathematical model and experiment of temperature effect on discharge of lead-acid battery for PV systems in tropical area. Energy And Power Engineering, 5, 43-49.

[8] Samolyk, M., \& Sobczak, J. (2013). Development of an algorithm for estimating Lead-Acid Battery State of Charge and State of Health. PhD Thesis. Blekinge Institute of Technology.

[9] Vutetakis, G., David, (2001). Douglas Battery. The Handbook Of Batteries \& Fuel Cells, Chapter: 10 David Linden, Third Edition.

[10] Author,'Title of the Paper", Journal name, Vol.X, No.X, (200X), pp.XX-XX, available online: http://xxx, last visit:28.02.2013 